Check for updates

Cite this: RSC Adv., 2017, 7, 29193

Received 25th April 2017

Accepted 27th May 2017

DOI: $10.1039 / c 7 r a 04660 j$

rsc.li/rsc-advances

\section{Sulfonic acid-grafted polyvinylidene fluoride electrospun mats as electro-Fenton reactor membrane components}

\author{
Yongxiang Zhuang, $\dagger^{a}$ Dan Li, ${ }^{a}$ Peipei Ding, ${ }^{a}$ Zhi Xu' and Wenheng Jing (iD *a
}

Electro-Fenton (EF) reactors, involving in situ generation of $\mathrm{H}_{2} \mathrm{O}_{2}$ by reaction of $\mathrm{O}_{2}$ in aqueous $\mathrm{Na}_{2} \mathrm{SO}_{4}$ upon applying voltage, show a number of advantages for organic pollutants degradation. The membrane, a key component of EF reactors, prevents $\mathrm{H}_{2} \mathrm{O}_{2}$ from being consumed in the anode. Recently, polyvinylidene fluoride (PVDF) nanofibers have emerged as promising membrane components, although the high interface impedance and low conductivity of these materials are serious drawbacks. Sulfonic acidgrafted PVDF nanofiber membranes can overcome these limitations. In this work, nanofiber PVDF membranes were prepared from electrospun single-fiber mats loaded on non-woven fabrics. In these fibers, the PVDF polymer was functionalized with sulfonic acid via covalent (3-mercaptopropyl) trimethoxysilane (MPS) bonding. These sulfonic acid-grafted PVDF nanofiber membranes showed a remarkable decrease in the water contact angle (WCA, from 120 to $6^{\circ}$ ), thereby greatly improving the hydrophilicity while reducing the membrane impedance (from $21.9 \Omega$ for the unmodified membrane to $15.7 \Omega$ for the acid-grafted material). Methyl orange (MO), a model pollutant, was completely EF removed within 30 min using the modified membrane. The modified membrane allowed a decrease of the electric

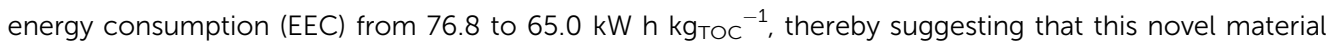
can provide an effective approach to improve the EF performance.

\section{Introduction}

Electro-Fenton (EF) is a highly efficient and environmentally friendly technology that has been widely applied in degrading toxic or biorefractory organic pollutants. ${ }^{1-3}$ The EF process is based on the electrochemical generation of powerful oxidizing agents such as hydroxyl radicals $\left({ }^{\circ} \mathrm{OH}\right)^{4}$ able to non-selectively degrade most organics into $\mathrm{CO}_{2}, \mathrm{H}_{2} \mathrm{O}$, and inorganic ions. ${ }^{5}$ During the EF process, ${ }^{\circ} \mathrm{OH}$ are produced via oxidation-reduction of the Fenton's reagent (i.e., $\mathrm{H}_{2} \mathrm{O}_{2}+\mathrm{Fe}^{2+}$ ). ${ }^{6}$ Therefore, the production and storage of $\mathrm{H}_{2} \mathrm{O}_{2}$ largely influences the EF performance.

In the EF process, $\mathrm{H}_{2} \mathrm{O}_{2}$ is generated by reaction of $\mathrm{O}_{2}$ on the surface of the cathode electrode under acid conditions. ${ }^{7}$ However, as a side effect, $\mathrm{H}_{2} \mathrm{O}_{2}$ is simultaneously consumed on the surface of anode electrode,${ }^{8}$ thereby reducing the utilization of $\mathrm{H}_{2} \mathrm{O}_{2}$. In this sense, a membrane is typically suggested to separate the anode and cathode electrodes. Different membranes (e.g., cationic, anionic, and Nafion-based) have

${ }^{a}$ State Key Laboratory of Materials-Oriented Chemical Engineering, Nanjing Tech University, 5 Xinmofan Road, Nanjing 210009, P. R. China. E-mail: jingwh@njtech. edu.cn; Fax: +86-25-8317-2292; Tel: +86-25-8358-9136

${ }^{b}$ Department of Engineering Science, University of Oxford, Old Road Campus Research Building, Headington, Oxford $O X 37 D Q, U K$

$\dagger$ Yongxiang Zhuang contributed to this work. been developed with the aim to improve the EF performance. ${ }^{\mathbf{1 , 9 , 1 0}}$ However, to be used under strong acid and oxidation environments, the EF membrane is required to present high conductivity and chemical stability. Therefore, enormous efforts have been devoted to develop high selectivity membranes for efficiently improving the EF performance.

Recently, PVDF nanofibers have emerged as promising membrane components for enhancing the EF process owing to their high chemical stability, high porosity, high dielectric constant, and low cost characteristics. ${ }^{\mathbf{1 1}}$ The open pore structure of PVDF nanofiber membranes facilitate ion transfer, thereby improving the membrane conductivity. ${ }^{12}$ However, PVDF membranes are typically hydrophobic, thereby providing these materials with high interface impedance and low conductivity characteristics. These drawbacks can be typically overcome by grafting on the membrane a hydrophilic group that serves also as a proton carrier, thereby enhancing the water and proton transfer phenomena. Especially, sulfonic acid-grafted PVDF membranes have attracted a great deal of attention as promising proton-conducting materials. ${ }^{\mathbf{1 3 1 4}}$ These materials are usually prepared by grafting styrene or substituted styrene monomers onto fluorinated polymer chains via electron beam radiation followed by sulfonation reactions. ${ }^{15-17}$ However, this method typically involves complex and costly equipment operation.

Considering the above, we used an easy-to-use grating method for preparing PVDF membranes. Taking advantage of 
the strong polarity of the $\mathrm{C}-\mathrm{F}$ bond, sodium hydroxide can be effectively used for introducing $(-\mathrm{OH})$ functional groups onto the fluoropolymer main chains. (3-Mercaptopropyl)trimethoxysilane (MPS) was subsequently grafted onto the PVDF-OH material via silanization reaction. The final sulfonic acidmodified PVDF ( $\mathrm{SO}_{3} \mathrm{H}-\mathrm{PVDF}$ ) membrane was obtained by oxidation with $\mathrm{H}_{2} \mathrm{O}_{2}$. The influence of the MPS concentration on the water contact angle (WCA) and the water flux was studied. The sulfonic acid-grafted PVDF nanofiber membrane with the optimum MPS content was further employed as a EF proton conducting membrane. Using methyl orange (MO) as a model pollutant, the performance (i.e., degradation rate and total organic carbon (TOC) removal) and electric energy consumption (EEC) of the EF system involving PVDF and $\mathrm{SO}_{3} \mathrm{H}-\mathrm{PVDF}$ membranes was discussed herein.

\section{Results and discussion}

\section{Morphology and properties of the PVDF electrospun mats}

As shown in Table 1, the viscosity of the spinning solution increased with the PVDF concentration. By increasing the PVDF concentration, the molecular weight of the polymer chains increased, thereby increasing the degree of molecular chain entanglement and the viscosity of the solution as a result.

The viscosity of the spinning solution has a significant influence on the morphology of the electrospun fiber. Thus, at low viscosities, the surface tension is well below the electric field force and the nanofibers generated were prone to breaking, thereby producing the spinning liquid to directly move to the receiving screen to form a bead. As clearly shown in Fig. 1a and

Table 1 Viscosity values for spinning solutions containing different concentrations of PVDF

\begin{tabular}{lll}
\hline Solvent & PVDF contents (wt\%) & Viscosity (cP) \\
\hline DMF & 15 & 163 \\
DMF & 18 & 278 \\
DMF & 20 & 374 \\
DMF & 22 & 628 \\
DMF & 24 & 815
\end{tabular}

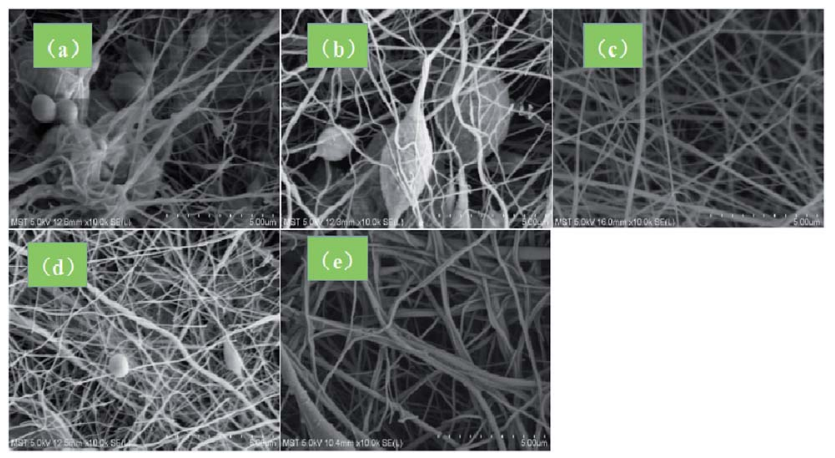

Fig. 1 SEM images the electrospun mats containing: (a) 15 wt\%, (b) 18 $w t \%$, (c) 20 wt\%, (d) 22 wt\%, and (e) 24 wt\% PVDF contents. b, a large number of beads were formed at low PVDF concentrations. In contrast, at very high viscosity values, the splitting power of the spinning solution was weakened and coarse fibers were formed since the electric field force needs to overcome the larger surface tension. In addition, the volatilization of the solvent was hindered while increasing the viscosity, thereby favoring nanofiber adhesion. As shown in Fig. 1e, non-uniform nanofibers were obtained at a PVDF concentration of $24 \mathrm{wt} \%$. However, bead-free nanofibers were obtained at $20 \mathrm{wt} \% \mathrm{PVDF}$ (Fig. 1c). Accordingly, a spinning solution containing $20 \mathrm{wt} \%$ PVDF was employed to prepare the PVDF nanofiber membrane.

The diameter distribution of the PVDF nanofibers was analyzed. As shown in Fig. 2a, the average nanofiber diameter was $132.57 \mathrm{~nm}$, while an average pore size of $0.29 \mu \mathrm{m}$ (Fig. 2b) was obtained by the bubble pressure method. Remarkably, the membrane exhibited a high porosity of $71.91 \%$, thereby potentially facilitating electrolyte uptake and ion transport through the membrane.

\section{Sulfonic acid-grafted PVDF electrospun nanofiber membrane}

Sulfonic acid groups were grafted onto the PVDF nanofiber membrane by a chemical route. As illustrated in Fig. 3a, the grafting reaction was accompanied with $\mathrm{HF}$ in the main chain to form $\mathrm{C}=\mathrm{C}$ double bonds serving as active sites for the introduction of hydrophilic hydroxyl groups. The silane coupling agent was subsequently introduced onto the surface of PVDF by reaction of the mercapto and the hydroxyl groups. Finally, sulfonic acid group-modified membranes were obtained by oxidation with $\mathrm{H}_{2} \mathrm{O}_{2}$.
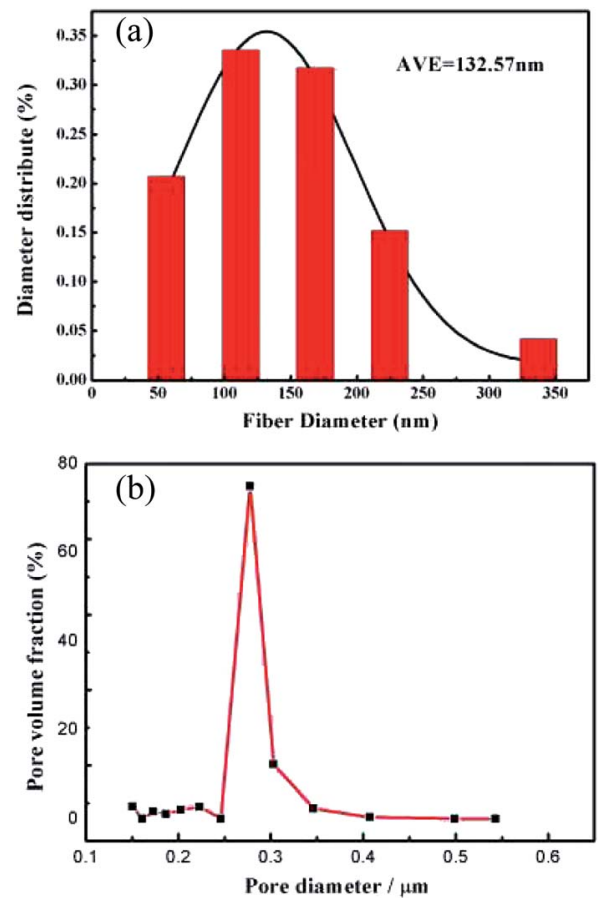

Fig. 2 (a) Fiber diameter and (b) pore diameter distributions of the PVDF nanofiber membranes. 
(a)

两

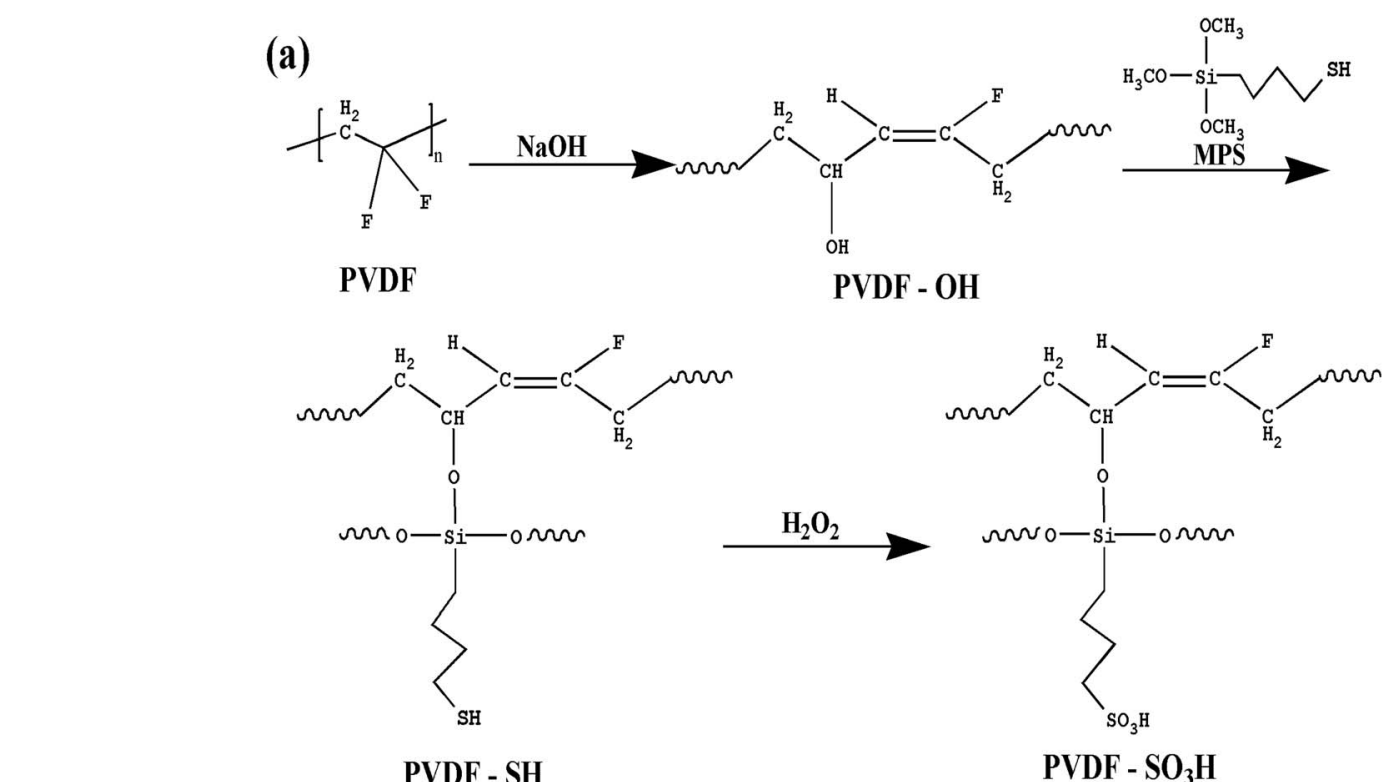

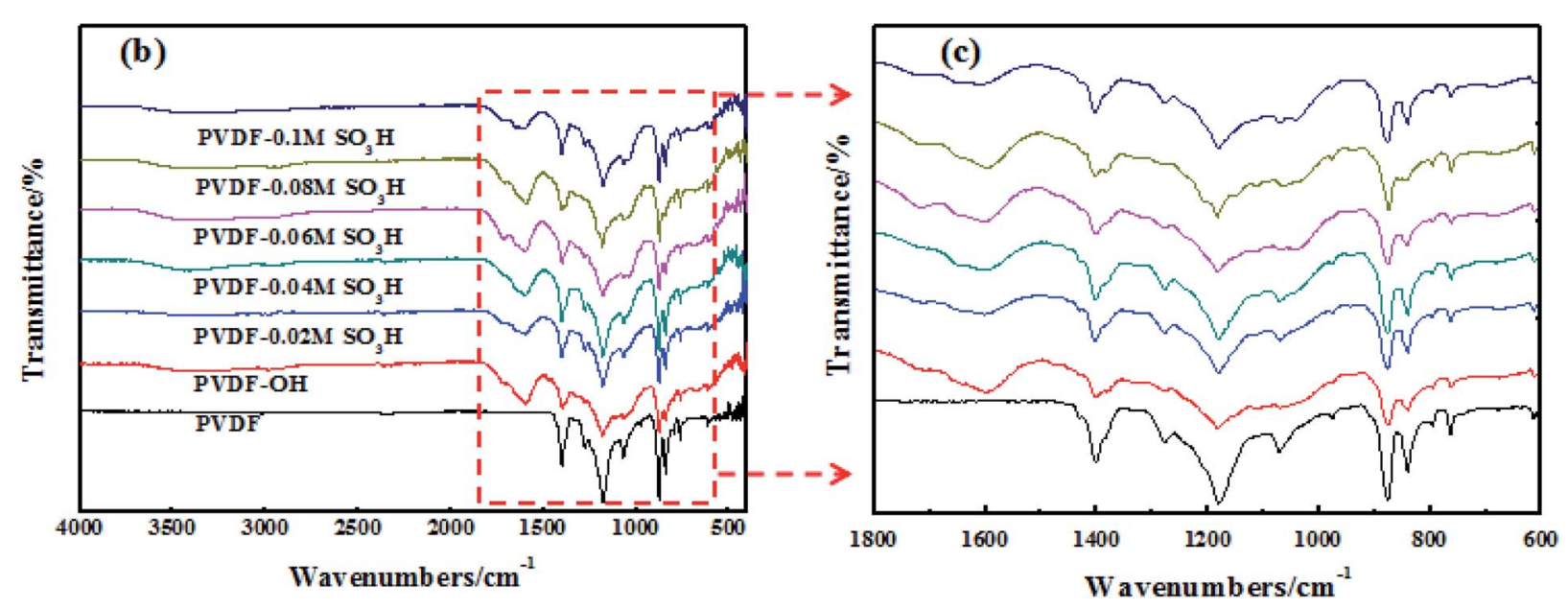

Fig. 3 (a) Schematic illustration of the synthesis route used to prepare the sulfonic acid-grafted PVDF membrane. FTIR spectra for the (b) PVDF and (c) PVDF- $\mathrm{SO}_{3} \mathrm{H}$ membranes.

The pristine and modified membranes were analyzed to verify that the grafting reaction took place, and the results are shown in Fig. $3 \mathrm{~b}$ and $\mathrm{c}$. As expected, $\mathrm{a} \mathrm{C}=\mathrm{C}$ characteristic peak was observed at $1600 \mathrm{~cm}^{-1}$ in the $\mathrm{NaOH}$-modified membranes. The Si-O-C characteristic peak was detected at $1080 \mathrm{~cm}^{-1}$ after silanization. In addition, the peaks characteristics of $-\mathrm{SO}_{3} \mathrm{H}$ were observed at 1043, 1110, 1151, and $1182 \mathrm{~cm}^{-1}$, and their intensity clearly increased with the MPS content of the feed. The above results indicated that $-\mathrm{SO}_{3} \mathrm{H}$ was successfully attached onto the PVDF chains through HF and silylation reactions of PVDF.

Subsequently, the wettability of the membrane surface was evaluated. The pristine membrane showed an hydrophobic behavior (WCA $=120^{\circ}$, Fig. $4 \mathrm{~b}$ ). This WCA value sharply decreased in the presence of sulfonic acid groups. As previously reported by numerous groups, ${ }^{19,20}$ the membrane became more hydrophilic with the MPC concentration and levelled off at a certain acid concentration. These resulted indicated that the wettability of the membrane surface was modified upon grafting sulfonic acid groups.

Hydrophilic surfaces typically promote water transport through the membrane. ${ }^{12}$ To further verify this hypothesis, we measured the pure water flux through the membrane (Fig. 4a). As expected, the water flux significantly enhanced in the presence of sulfonic acid groups. The water flux through the modified membrane continuously increased with the acid concentration up to $0.08 \mathrm{~mol} \mathrm{~L}^{-1}$ and levelled off thereafter. Thus, the concentration of hydroxyl groups on the membrane surface was saturated at an acid concentration of $0.08 \mathrm{~mol} \mathrm{~L}^{-1}$. This concentration was therefore selected as the optimum value for the silylation reaction. 
(a)

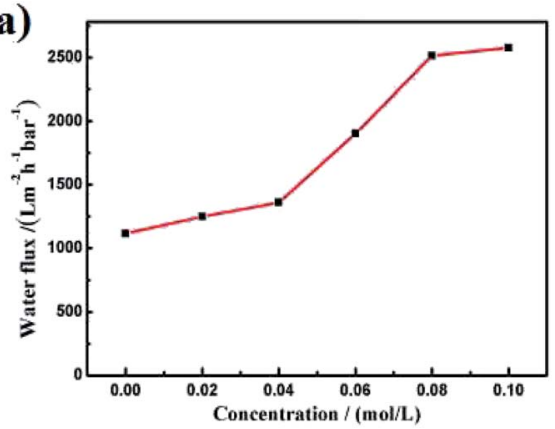

(b)

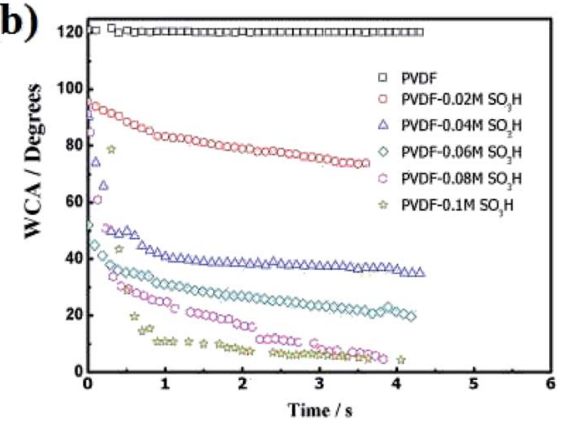

Fig. 4 (a) Water flux and (b) WCA of the PVDF nanofiber membrane at different MPS concentrations.

\section{Sulfonic acid-PVDF electrospun membrane in the EF system}

While the EF reaction mechanism is highly complex (Fig. 6), the main reactions involved can be described as follows: ${ }^{21-23}$
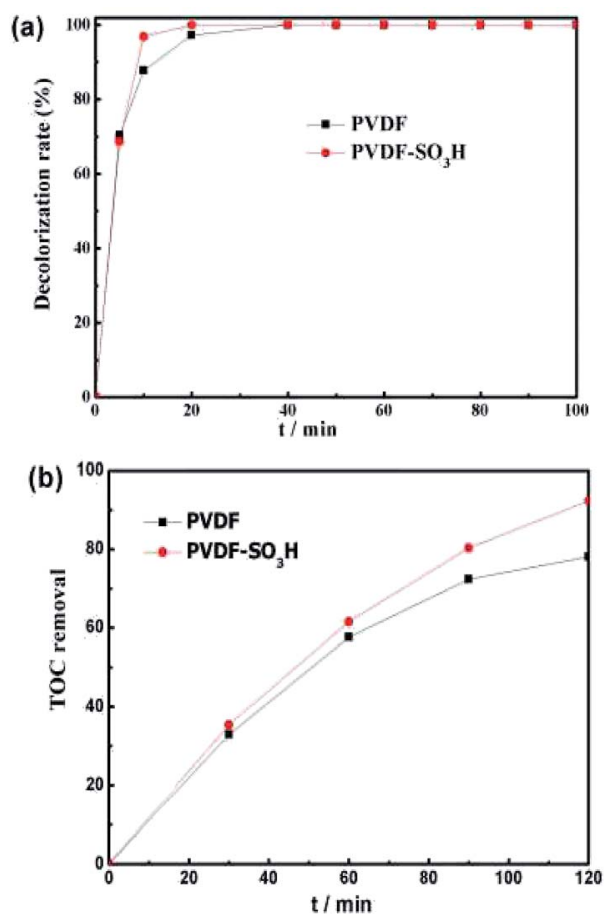

Fig. 5 (a) Decoloration of $\mathrm{MO}$ and (b) TOC removal for different membranes at divided flow cell. Conditions: $V=100 \mathrm{~mL}$; $[\mathrm{MO}]=$ $0.1 \mathrm{mM} ;\left[\mathrm{Fe}^{2+}\right]=0.2 \mathrm{mM} ; \mathrm{pH}=3 ;\left[\mathrm{H}_{2} \mathrm{SO}_{4}\right]=5 \mathrm{mM}$; and $I=-50 \mathrm{~mA}$.

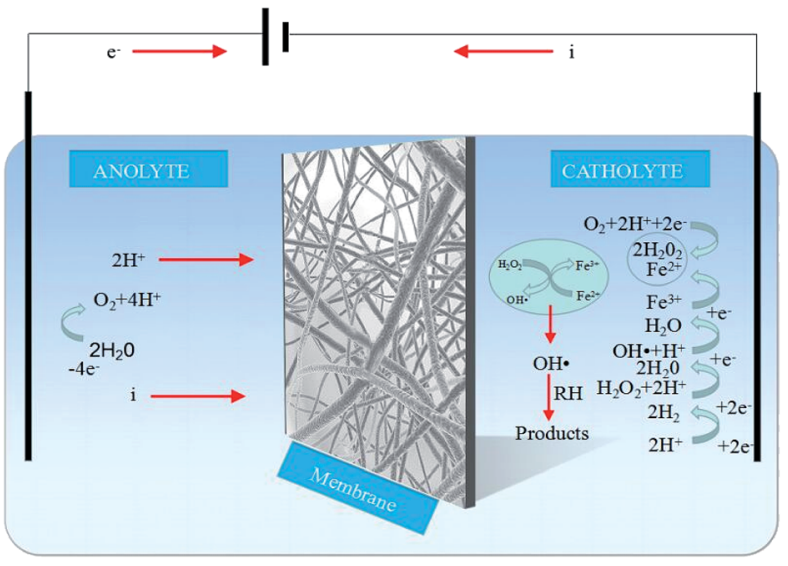

Fig. 6 Reaction mechanism of the EF process.

$$
\begin{gathered}
\mathrm{O}_{2}+2 \mathrm{H}^{+}+2 \mathrm{e}^{-} \rightarrow \mathrm{H}_{2} \mathrm{O}_{2} \\
\mathrm{H}_{2} \mathrm{O}_{2}+\mathrm{Fe}^{2+}+\mathrm{H}^{+} \rightarrow \mathrm{Fe}^{3+}+\cdot \mathrm{OH}+\mathrm{H}_{2} \mathrm{O} \\
\mathrm{Fe}^{3+}+\mathrm{e}^{-} \rightarrow \mathrm{Fe}^{2+} \\
\mathrm{OH}+\mathrm{RH} \rightarrow \mathrm{R}^{\cdot}+\mathrm{H}_{2} \mathrm{O}
\end{gathered}
$$

The performance of the electrospun nanofiber membranes in the EF system was evaluated by selecting $\mathrm{MO}$ as the model

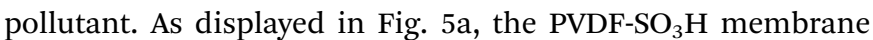
showed a high degradation efficiency of $96.9 \%$ after $10 \mathrm{~min}$. The

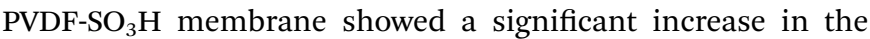
efficiency at the initial stage of reaction as compared to the pristine material. These results might be ascribed to the higher conductivity of the PVDF polymer in the presence of sulfonic acid groups, which promoted the production of $\mathrm{H}_{2} \mathrm{O}_{2}$ and ${ }^{\circ} \mathrm{OH}$. The TOC removal also increased for the $\mathrm{PVDF}^{-} \mathrm{SO}_{3} \mathrm{H}$ membrane as compared to the pristine material (92.3 vs. $78.1 \%$, Fig. $5 \mathrm{~b})$.

For practical engineering applications involving pollutant mineralization, the energy consumption is an important factor. Fig. 7 shows the EEC value of the membranes as a function of time. Remarkably, the modified membrane showed lower EEC values for the EF process as compared to the pristine material, and these values were significantly lower than those showed by other TOC removal technologies published in the literature

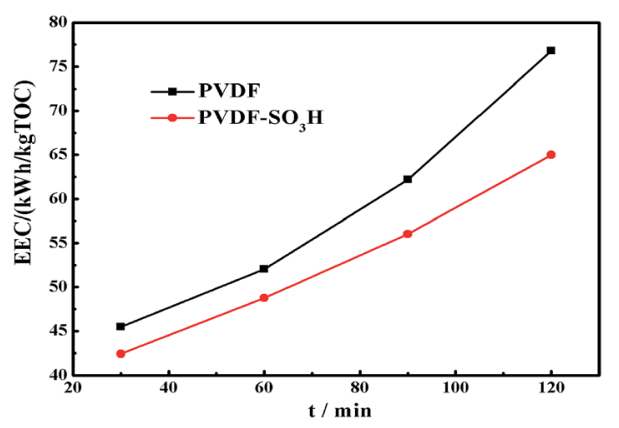

Fig. 7 EEC in the EF process for both membranes under study. 
Table 2 Comparison of the EEC values of different TOC removal technologies published in literatures

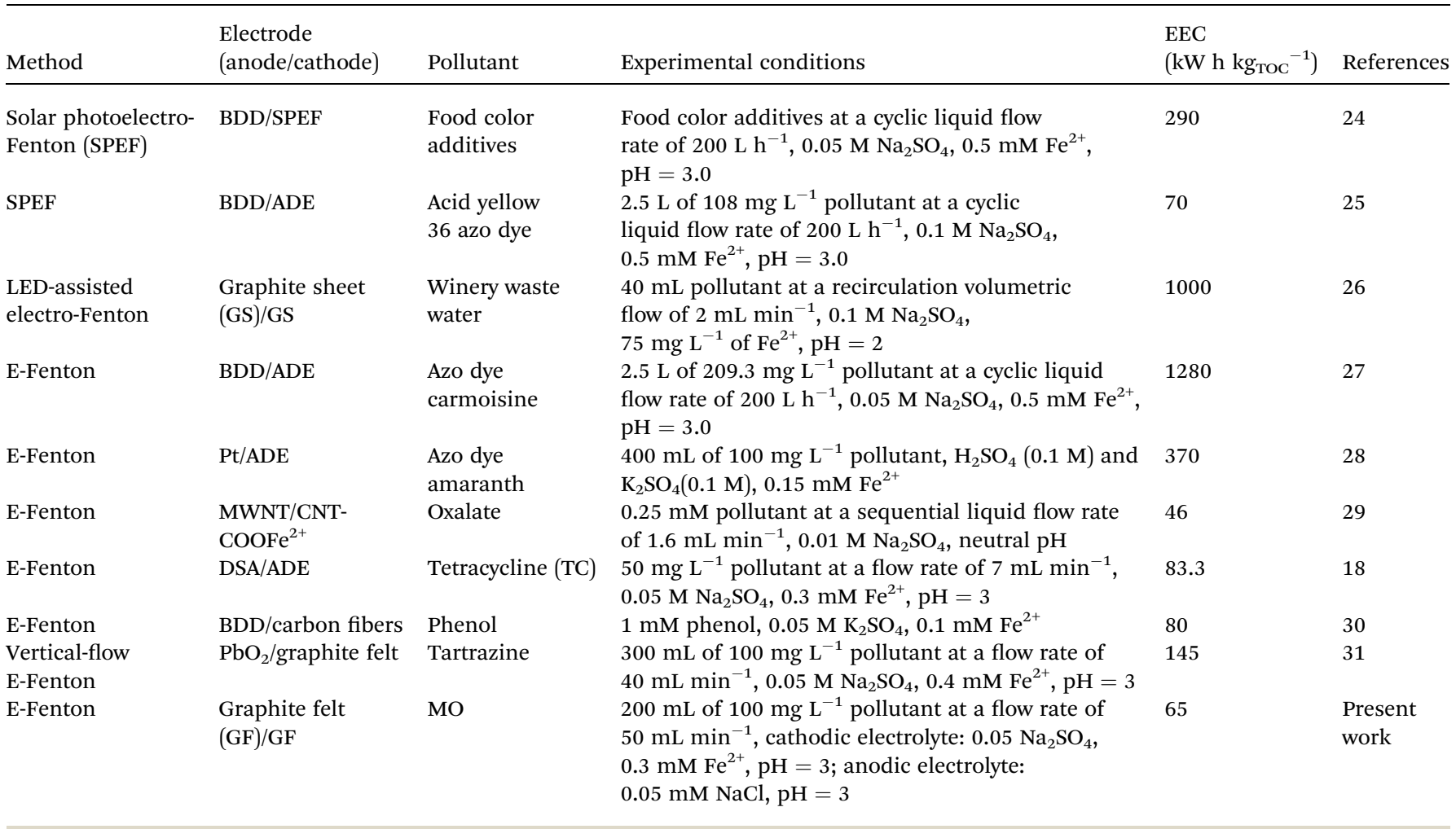

(Table 2). In addition, the stability of the $\mathrm{PVDF}_{-} \mathrm{SO}_{3} \mathrm{H}$ membrane was tested. The modified membrane presented a fine longcycling stability performance and its re-usability, as shown in

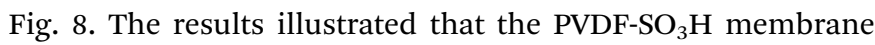
prepared herein can be suitable for EF applications with high degradation efficiency and low energy consumption.

EIS measurements were carried out to explain the low EEC values of the $\mathrm{PVDF}_{-} \mathrm{SO}_{3} \mathrm{H}$ membrane. As shown in Fig. 9, the ohmic resistance of the pristine $\mathrm{PVDF}$ and $\mathrm{PVDF}_{-} \mathrm{SO}_{3} \mathrm{H}$ membranes were 21.9 and $15.7 \Omega$, respectively. Thus, the ohmic resistance significantly decreased upon $-\mathrm{SO}_{3} \mathrm{H}$ grafting. The hydrophilicity of the PVDF membrane was improved after modified by the $-\mathrm{SO}_{3} \mathrm{H}$ groups, thereby promote the water transfer through the membrane, which led to the acceleration of ion transport in the channel of membrane. ${ }^{1}$ Meanwhile, the

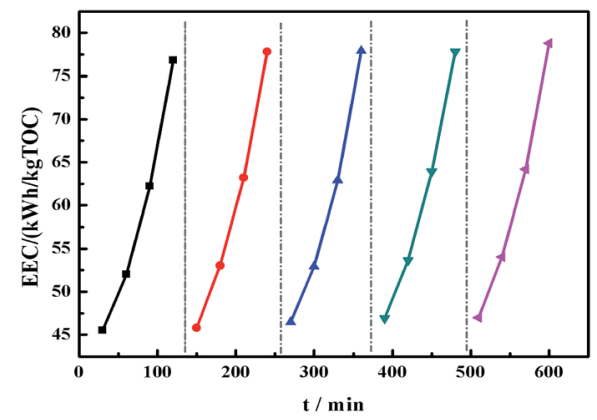

Fig. 8 EEC in the EF process for 5 consecutive experiments with the PVDF- $\mathrm{SO}_{3} \mathrm{H}$ membrane.

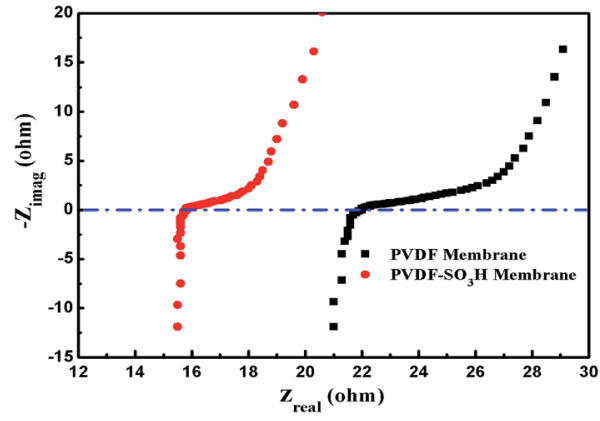

Fig. 9 Ohmic impedance of the pristine PVDF and $\mathrm{PVDF}-\mathrm{SO}_{3} \mathrm{H}$ membranes.

sulfonic acid groups attached on the polymer chains can serve as proton sources, contributes significantly to proton conduction. ${ }^{2,3}$ And also, the negatively charged $\mathrm{SO}^{3-}$ groups also coordinate with the cations, promoting the dissociation of the electrolytes. ${ }^{1}$ These effects allow significantly reducing the internal membrane resistance value.

\section{Experimental section}

\section{Materials}

All the chemicals used in this study were of analytical grade and used as received without further purification. PVDF (average $M_{\mathrm{n}}$ : ca. 400000 , Sigma-Aldrich) and $N, N$-dimethylformamide (DMF, $\geq 99.5 \%$, Sinopharm Chemical Reagent Co., Ltd) were used to 
prepare the electrospun nanofiber solution. Sodium hydroxide ( $\mathrm{NaOH}$, 96\%, Sinopharm Chemical Reagent Co., Ltd), $\mathrm{H}_{2} \mathrm{O}_{2}$ (30\%, Sinopharm Chemical Reagent Co., Ltd), and MPS (98\%, Sigma-Aldrich) were used to modify the surface properties of the electrospun nanofiber mats. Furthermore, sodium chloride $(\mathrm{NaCl})$, sodium sulfate $\left(\mathrm{Na}_{2} \mathrm{SO}_{4}\right)$, hydrogen chloride $(\mathrm{HCl})$, sulfuric acid $\left(\mathrm{H}_{2} \mathrm{SO}_{4}\right)$, ferrous sulfate heptahydrate $\left(\mathrm{FeSO}_{4} \cdot 7 \mathrm{H}_{2}\right.$ O), MO (Tianjin Chemical Reagent Research Institute) as a model pollutant, graphite felt (GF) (Shanghai Hong Jun Industry Co., Ltd) with a carbon content of $99.9 \%$ as an electrode material, and deionized water were used for the EF experiments.

\section{Preparation of the PVDF nanofibers}

PVDF was dissolved in DMF at varying concentration $(15,18,20$, 22 , and $24 \mathrm{wt} \%$ ) and stirred at $60{ }^{\circ} \mathrm{C}$ for $12 \mathrm{~h}$ to obtain homogenous spinning solutions. The solutions were subsequently filled in a plastic syringe and used to fabricate the nanofiber membranes with a laboratory scale electrospinning apparatus (schematically shown in Fig. 10) at $25{ }^{\circ} \mathrm{C}, 45 \%$ relative humidity ( $\mathrm{RH}$ ), a voltage of $20 \mathrm{kV}$, a flow rate of $1.0 \mathrm{~mL} \mathrm{~h}^{-1}$, and a distance of $15 \mathrm{~cm}$ between the spinneret and the collector. The collected electrospun nanofiber membranes were vacuum dried at $80{ }^{\circ} \mathrm{C}$ for $12 \mathrm{~h}$ and subsequently stored until use.

\section{Grafting of the sulfonic acid groups onto the PVDF nanofiber membranes}

$\mathrm{NaOH}$ was dissolved in a $6 \mathrm{M}$ ethanol aqueous solution at a volume ratio of $1: 1$. The membrane was subsequently immersed in this solution at $60{ }^{\circ} \mathrm{C}$ for $8 \mathrm{~h}$ to promote dehydrofluorination (HF) and introduce hydroxyl groups. The membrane was repeatedly washed with deionized water until neutral $\mathrm{pH}$, and subsequently dried at $105{ }^{\circ} \mathrm{C}$ for $1 \mathrm{~h}$. Silane coupling agents with different concentrations ranging from 0.02 to $0.08 \mathrm{M}$ were dissolved in ethanol. Acetic acid (i.e., a hydrolysis catalyst) was added to the above solution to adjust the $\mathrm{pH}$ value at 3.5-5.5. After stirring for $1 \mathrm{~h}$ at $25{ }^{\circ} \mathrm{C}$, a homogenous solution was obtained. Subsequently, the dried nanofiber membranes were immersed in the as-obtained solution and allowed to react for $10 \mathrm{~h}$ in a constant temperature oscillator at $60^{\circ} \mathrm{C}$. Subsequently, the membrane was thoroughly rinsed with ethanol and vacuum dried at $110{ }^{\circ} \mathrm{C}$ for an hour to completely remove the solvent.

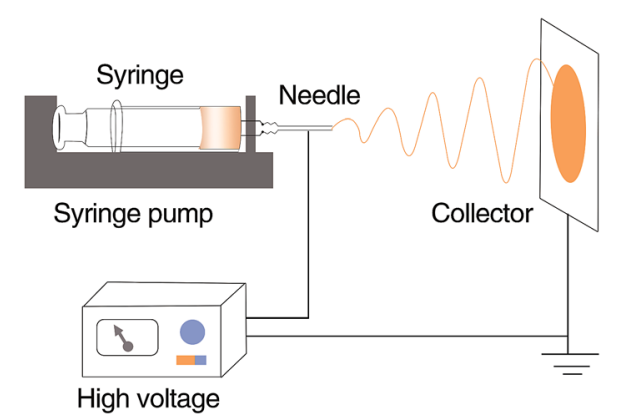

Fig. 10 Schematic of the electrospinning apparatus used herein.
Finally, the above membranes were soaked with a 2 wt $\%$ hydrogen peroxide aqueous solution to promote oxidation of mercapto groups to sulfonic acid in constant temperature oscillator at $60{ }^{\circ} \mathrm{C}$. After $8 \mathrm{~h}$, the membrane surface was rinsed with deionized water and subsequently dried at $110{ }^{\circ} \mathrm{C}$ for $1 \mathrm{~h}$. All the modified membranes were stored in distilled water before being used.

\section{Characterization}

The viscosity of the spinning solution was determined using a rotary viscometer (DV-II+, Brookfield, USA) at $25{ }^{\circ} \mathrm{C}$. Fourier transform infrared (FTIR) spectra were obtained on a PerkinElmer instruments Spectrum GX FTIR spectrometer provided with an attenuated total reflection (ATR) attachment operating in the transmittance mode in a wavenumber range of $400-4000 \mathrm{~cm}^{-1}$. Field emission scanning electron microscopy (FE-SEM, Hitachi S4800) was used to observe the surface morphology of the membrane. To measure the average diameter of the membrane nanofibers, 100 fibers from the SEM micrograph were randomly selected to prepare a diameter distribution. The hydrophilicity of the membranes was measured on a video optical contact angle tester (Drop Meter A-100p, China). The membrane permeability was determined by measuring the permeation of deionized water at a transmembrane pressure of $0.1 \mathrm{MPa}$. The porosity of the electrospun fiber membrane was determined by the Archimedes method by immersing the dry membrane in $n$-butanol for $3 \mathrm{~h}$, and the porosity was calculated by the following equation:

$$
P \%=\frac{W_{\mathrm{W}}-W_{\mathrm{d}}}{\rho_{\mathrm{b}} \times V_{\mathrm{m}}} \times 100 \%
$$

where $W_{\mathrm{W}}$ is the mass of the absorbed $n$-butanol, $W_{\mathrm{d}}$ is the mass of pristine membrane, $V_{\mathrm{m}}$ is the volume of electrospun fiber membrane, and $\rho_{\mathrm{b}}$ is the density of $n$-butanol.

\section{Electrochemical impedance spectroscopy (EIS) measurements}

EIS measurements were carried out on a electrochemical workstation (GAMRY Instruments Reference 3000). The sinusoidal excitation voltage applied to the EF system was $0.01 \mathrm{~V}$, while the frequency ranged from 0.1 to $1000 \mathrm{kHz}$.

\section{MO decoloration degradation tests in the EF system}

Degradation of MO was carried out in a circular doublechamber cell reactor schematically shown in Fig. 11. A -50 $\mathrm{mA}$ galvanostatic electrolysis was also conducted in the reactor by using the electrochemical workstation. GF was employed as both cathode and anode material. The anode cell was filled with a $50 \mathrm{mM} \mathrm{NaCl}$ solution and the $\mathrm{pH}$ was adjusted to 3 with a $\mathrm{HCl}$ solution, while the cathode cell was filled with $0.2 \mathrm{mmol} \mathrm{L}^{-1}$ $\mathrm{FeSO}_{4} \cdot 7 \mathrm{H}_{2} \mathrm{O}$ and $50 \mathrm{mM} \mathrm{Na} \mathrm{SO}_{4}$ solutions and the $\mathrm{pH}$ was adjusted to 3 with a $\mathrm{H}_{2} \mathrm{SO}_{4}$ solution. ${ }^{18}$ Pure $\mathrm{O}_{2}$ was bubbled before starting the EF oxidation into the cathode storage tank for $10 \mathrm{~min}$ to generate a highly dissolved oxygen concentration in the cathode and thereby enhance the $\mathrm{H}_{2} \mathrm{O}_{2}$ production. A peristaltic pump with a running speed of $50 \mathrm{~mL} \mathrm{~min}^{-1}$ was used to re-circle the solutions. The concentration of MO was monitored by determining the absorbance at $463 \mathrm{~nm}$ on a UV-vis 


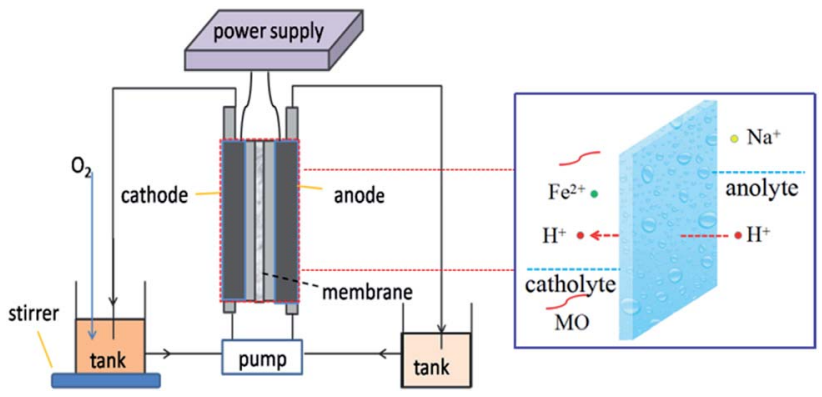

Fig. 11 Schematic diagram of the double-chamber cell reactor operating in batch recirculation mode.

spectrophotometer (UV759, Shanghai Instrument Analysis Instrument Co., Ltd). The TOC of the solution was determined on a Phoenix 8000 TOC analyzer. With the aim to monitor the decolorization/degradation and TOC removal rate of MO, aliquots were withdrawn from the reactor at regular time intervals (i.e., 0, 5, 10, 20, 40, 60, 90, and $120 \mathrm{~min}$ ) and subsequently analyzed.

The EEC was calculated with the following formula: ${ }^{18}$

$$
\operatorname{EEC~}\left(\mathrm{kW} \mathrm{h} \mathrm{kg}_{\mathrm{TOC}^{-1}}{ }^{-1}=\frac{1000 U I t}{V(\Delta \mathrm{TOC})_{\exp }}\right.
$$

where $U$ is the voltage (V), $I$ is the applied current (A), $t$ is the electrolysis time (h), $V$ is the volume (L), and $\Delta(\text { TOC) })_{\exp }$ is the experimental TOC removal $\left(\mathrm{mg} \mathrm{L}^{-1}\right)$.

\section{Conclusions}

We reported an effective method for modifying electrospun nanofiber membranes with the aim to increase their hydrophilic performance and obtain excellent electrical conductivity in EF systems. Strong hydrophilicity and fast electron transportation were achieved by the modified samples, thereby efficiently improving the electrocatalytic EF activity. When modified at the optimal concentration of $0.08 \mathrm{M}$ of MPS, the WCA of the membrane decreased from 120 to $6^{\circ}$, thereby greatly improving its hydrophilicity while also reducing the membrane impedance (from 21.9 to $15.7 \Omega$ ). Starting with $50 \mathrm{mg} \mathrm{L}^{-1}$ of $\mathrm{MO}$ as the model pollutant, the pristine PVDF and $\mathrm{PVDF}^{-\mathrm{SO}_{3} \mathrm{H}}$ membranes showed degradation efficiencies of 87.7 and $96.9 \%$ after $10 \mathrm{~min}$, respectively. The TOC removal ratio of the pristine and modified materials reached 78.1 and $92.3 \%$ after $2 \mathrm{~h}$, respectively. The modified membrane achieved significantly greater MO degradation and TOC removal rates within the EF system as compared to the untreated material. Thus, the reported modification methodology is a promising membrane modification alternative to improve the conductivity of EF systems.

\section{Acknowledgements}

This work is financially supported by the National Natural Science Foundation of China (21676139), the Higher Education
Natural Science Foundation of Jiangsu Province (15KJA530001), the Project of Priority Academic Program Development of Jiangsu Higher Education Institutions (PAPD) and Research Fund of state key Laboratory of Materials-Oriented Chemical Engineering (ZK201604).

\section{Notes and references}

1 I. S. E. B. Oturan and M. A. R. M. Panizza, Environ. Sci. Pollut. Res., 2014, 21, 8336-8367.

2 P. V. Nidheesh, Desalination, 2012, 299, 1-15.

3 F. C. Moreira, R. A. R. Boaventura, E. Brillas and V. J. P. Vilar, Appl. Catal., B, 2017, 202, 217-261.

4 Z.-X. Wang, Carbohydr. Polym., 2011, 86, 1807-1813.

5 A. Maoa, Crit. Rev. Environ. Sci. Technol., 2014, 44, 2577-2641. 6 E. Brillas, Chem. Rev., 2009, 109, 6570-6631.

7 H. Zhao, Y. Chen, Q. Peng, Q. Wang and G. Zhao, Appl. Catal., B, 2017, 203, 127-137.

8 S. Ignasi and N. Oturan, Appl. Catal., B, 2007, 72, 382-394.

9 D. P. Anna and D. P. Luca, J. Appl. Electrochem., 2005, 35, 413-419.

10 X. Li, X. Jin, N. Zhao, I. Angelidaki and Y. Zhang, Bioresour. Technol., 2017, 228, 322-329.

11 D. M. A. J. Pedro Zapata, Macromolecules, 2010, 43, 76257636.

12 R. Zhou, W. Liu and W. L. Yew, ACS Appl. Mater. Interfaces, 2015, 7, 16548-16557.

13 H. Li, Y. Lee, J. Lai and Y. Liu, J. Membr. Sci., 2014, 466, 238245.

14 Y. Su, Y. Liu, D. Wang, J. Lai, Y. Sun, S. Chyou and W. Lee, J. Membr. Sci., 2010, 349(1-2), 244-250.

15 M. P. A. F. Sundholm, Chem. Mater., 2003, 15, 4447-4455.

16 S. Hietala, S. Holmberg, M. N. Karjalainen, J. Sman, M. Paronen, R. Serimaa, F. Sundholm and S. Vahvaselk, J. Mater. Chem., 1997, 7(5), 721-726.

17 C. C. Ami and A. R. Yang, J. Membr. Sci., 2014, 469, 251-261. 18 L. Ma and M. H. Zhou, Electrochim. Acta, 2016, 200, 222-230. 19 B. G. Nathaniel and B. Baro, J. Membr. Sci., 2007, 290, 46-54. 20 A. Faheem and M. A. Sheikha, Appl. Surf. Sci., 2016, 385, 417425.

21 O. I. E. R. Sanromán, Environ. Sci. Pollut. Res., 2013, 20, 22522261.

22 A. R. Khataee, J. Hazard. Mater., 2009, 161, 1225-1233.

23 B. N. B. B. Samiha Hammamia, Chemosphere, 2008, 73, 678684.

24 I. S. E. E. Abdoulaye Thiam, Water Res., 2015, 81, 178-187. 25 J. Edgar and A. Ruiz, Chemosphere, 2011, 82, 495-501.

26 A. M. Díez, Chem. Eng. J., 2017, 310, 399-406.

27 I. S. J. A. Abdoulaye Thiam, Sep. Purif. Technol., 2015, 140, 43-52.

28 R. P. Willyam and P. C. Barros, J. Electroanal. Chem., 2014, 722-723, 46-53.

29 Q. Z. Z. H. Guandao Gao, Environ. Sci. Technol., 2015, 49, 2375-2383.

30 E. Mousset, Water Sci. Technol., 2016, 74, 2068-2074.

31 M. Z. M. L. Gengbo Ren, Chem. Eng. J., 2016, 298, 55-67. 